NBER WORKING PAPER SERIES

\title{
MONITORING, MOTIVATION AND MANAGEMENT: \\ THE DETERMINANTS OF OPPORTUNISTIC BEHAVIOR IN A FIELD EXPERIMENT
}

\author{
Daniel Nagin \\ James Rebitzer \\ Seth Sanders \\ Lowell Taylor \\ Working Paper 8811 \\ http://www.nber.org/papers/w8811 \\ NATIONAL BUREAU OF ECONOMIC RESEARCH \\ 1050 Massachusetts Avenue \\ Cambridge, MA 02138 \\ March 2002
}

We would like to thank the following people for helpful advice and criticism: Dan Black; John Bound, Robert Frank, Dan Hammermesh, Ed Lazear, and Yoram Weiss. We also benefited from comments received during presentations at: the Society for Labor Economists meetings, the NBER Summer Institute, Case Western Reserve University's Markets, Organizations and Public Policy seminar, and Princeton University's Industrial Relations seminar. Laura Leete graciously provided the census extracts we use in our analysis. The views expressed herein are those of the authors and not necessarily those of the National Bureau of Economic Research.

(C) 2002 by Daniel Nagin, James Rebitzer, Seth Sanders and Lowell Taylor. All rights reserved. Short sections of text, not to exceed two paragraphs, may be quoted without explicit permission provided that full credit, including $\mathbb{C}$ notice, is given to the source. 
Monitoring, Motivation and Management: The Determinants of Opportunistic Behavior in a Field Experiment

Daniel Nagin, James Rebitzer, Seth Sanders and Lowell Taylor

NBER Working Paper No. 8811

March 2002

JEL No. D2, J2, L2, L8, M12

\begin{abstract}
Economic models of incentives in employment relationships are based on a specific theory of motivation. Employees are "rational cheaters," who anticipate the consequences of their actions and shirk when the perceived marginal benefit exceeds the marginal cost. Managers respond to this decision calculus by implementing monitoring and incentive pay practices that lessen the attraction of shirking. This "rational cheater model" is not the only model of opportunistic behavior, and indeed is viewed skeptically by human resource practitioners and by many non-economists who study employment relationships.

We investigate the "rational cheater model" using data from a double-blind field experiment that allows us to observe the effect of experimentally-induced variations in monitoring on employee opportunism. The experiment is unique in that it occurs in the context of an ongoing employment relationship, i.e., with the firm's employees producing output as usual under the supervision of their front-line managers. The results indicate that a significant fraction of employees behave roughly in ccordance with the "rational cheater model." We also find, however, that a substantial proportion of employees do not respond to manipulations in the monitoring rate. This heterogeneity is related to employee assessments about their general treatment by the emp loyer.
\end{abstract}

Daniel Nagin

H. John Heinz III School of Public Policy and Management

Carnegie Mellon University

Pittsburgh, PA 15213-3890

Seth Sanders

Department of Economics

University of Maryland

College Park, MD 20742
James Rebitzer

Weatherhead School of Management

Case Western Reserve University

10900 Euclid Ave.

Cleveland, OH 44106

and NBER

Lowell Taylor

H. John Heinz III School of Public Policy

and Management

Carnegie Mellon University

Pittsburgh, PA 15213-3890 


\section{Introduction}

Economic models of incentives in employment relationships are based on a very specific theory of motivation. Employees are "rational cheaters." They anticipate the consequences of their actions and shirk when the perceived marginal benefit of doing so exceeds the marginal cost. Firms respond to this decision calculus by implementing monitoring and incentive pay policies that make shirking unprofitable.

Although the "rational cheater" model is ubiquitous in economics, it is often viewed skeptically by human resource practitioners and the other social science disciplines that study employment relationships (see Baron and Kreps, 1999, Kreps, 1997, March, 1994, and Pfeffer, 1996). The validity of the rational cheater model is an empirical question that is, in principle, easy to investigate. If employees are rational cheats then, conditional on a given incentive pay arrangement, a reduction in monitoring will lead to an increase in shirking. The most powerful sanction available to employers is typically dismissal. Thus, an increase in shirking resulting from reduced monitoring should be greatest among individuals for whom the ongoing employment relationship is least valuable.

Empirical investigation of the rational cheater model is hindered by two almost insurmountable problems. First, truly rational cheaters are most likely to engage in shirking behavior when it is hard or expensive to detect. Second, should any association between monitoring and employee actions be found, it will be very difficult to disentangle the effects of monitoring strategies from responses to other, unobserved features of the firm's employees or its human resource system. Resolving these problems requires an experimental setting in which monitoring levels are exogenously varied across similar sites and substantial resources are devoted to tracking the behaviors of employees (Rebitzer 1995).

This paper presents the results of just such an experiment. The data were collected by a large telephone solicitation company. The employees in this company work at 16 geographically dispersed sites. At each call center, telephone solicitors were paid according to the same 
modified piece rate incentive scheme, one in which salary increased with the number of successful solicitations. ${ }^{1}$ This piece rate, together with imperfect information on the outcome of pledges, created incentives for employees to falsely claim that they had solicited a donation. ${ }^{2}$ To curb opportunistic behavior, the employer monitored for false donations by calling back a fraction of those who had responded positively to a solicitation. "Bad calls" were calls in which donations previously reported by employees were repudiated by donors.

Employees at the company were informed when hired that their activities would be checked by “call backs" made by management at the company's central headquarters. The results of each week's call backs were communicated to both employees and their immediate supervisors, and the bad calls were deducted from each individual's weekly incentive pay. Stronger sanctions for bad calls were not generally imposed on employees because the number of bad calls was a noisy indicator of cheating. The noise resulted from the fact that donors sometimes changed their mind after agreeing to pledge money.

The costs of call backs are substantial; each audit costs as much as the original solicitation call. To reduce these monitoring costs, the $\mathrm{CEO}$ of the firm wanted to operate with as small an audit rate as necessary. In an attempt to study the effects of reducing oversight, the company conducted a controlled field experiment. This experiment was "double blind" in the sense that neither the employees nor their immediate supervisors were aware of departures from "business as usual." In the experiment, the employer varied the fraction of bad calls that were reported back to employees and supervisors at each of its 16 calling units (what we call the

1 During the period of the study, all solicitations were requests for donations to not-for-profit organizations.

2 At the time of this study, the company's computer system could not generate reports linking the outcome of a pledge to an individual caller. In addition, the CEO of the company did not think it right for employees to bear the risk associated with unfulfilled donations. It typically took weeks (and sometimes months) to collect the money promised in a donation. The CEO believed that asking employees to postpone bonuses until the donated money arrived would undermine the effectiveness of the incentive pay. For all these reasons, the company paid employees their incentive pay prior to receipt of the money promised. 
observable monitoring rate), while at the same time increasing the true call back rate from $10 \%$ to $25 \%$ of pledges for the purpose of increasing the precision of the estimate of the true rate of fictitious pledges. By analyzing the effect of varying the "observable monitoring rate," the employer hoped to learn the consequences of reduced monitoring on employee behavior.

The employer made available to us the results of the experiment. In addition, the employer allowed us to collect survey data on employee attitudes towards the job, their expected job tenure, and the perceived difficulty of finding another, comparable job. Other information collected in the survey (age, gender, work hours, educational attainment, whether an employee is also a student, locati on of the call center) allow us to estimate outside earnings opportunities for each individual. By matching estimates of outside options and employee perceptions with employee behaviors under different monitoring regimes, we can evaluate whether the employees for whom the job was most valuable were also the employees least likely to engage in opportunistic behavior.

The experiment we analyze in this paper spans two lines of empirical research on incentives. The first line of research consists of empirical studies of how work hours, effort, productivity, or firm performance respond to monetary rewards. ${ }^{3}$ Our research differs from these studies in a number of important ways. The first and most obvious difference is that the variation in incentives is exogenously induced in this study and not in most others. A second difference is that our study makes use of direct measures of opportunistic behavior, whereas most field studies rely on indirect measures. A third and more subtle difference concerns the nature of the variation in incentives. Rather than manipulating monetary payoffs, this

3 Examples of this literature include Berman (2000), Bewley (2000), Cammerer, et al. (1997), Cappelli and Chauvin (1992), Encinosa, Gaynor and Rebitzer (2000), Gaynor, Rebitzer and Taylor (2001), Hall and Liebman (1998), Landers, Rebitzer and Taylor (1996), and Lazear (2000). Some of these studies find that employees respond to incentives in ways that are roughly consistent with the economic model of opportunistic behavior, while others emphasize findings that are anomalous from the perspective of conventional economic explanations. Prendergast (1999) provides a review of the literature. 
experiment varied monitoring rates. While every employee of the company knew that their reported "sales" could be checked, they did not know the actual intensity of monitoring but rather had to infer monitoring rates from their own experience. Because the employee systematically varied both monitoring rates and the reporting of the results of the monitoring to employees, this experiment can shed some light on the degree to which employees actively seek out opportunities for shirking.

The second body of literature relevant to our study concerns laboratory studies of cooperative and opportunistic behavior. These studies find that in some laboratory settings individuals act in accordance with the rational cheater model, but that in other settings individuals engage in less opportunism than the economic model predicts (e.g., Bazerman, Gibbons, Thompson and Valley, 1998, and Camerer and Thaler, 1995). The singular shortcoming of most laboratory studies is that they do not take place in the context of a persistent economic relationship. ${ }^{4}$ In contrast, this experiment involves manipulating incentives within an ongoing, real world, employment relationship.

The results of the experiment suggest that a significant fraction of employees behave according to the predictions of the rational cheater model. Specifically, we find that these employees respond to a reduction in the perceived cost of opportunistic behavior by increasing the rate at which they shirk. On the other hand, we did not find that individuals with good outside options increased shirking by more than other workers when the rate of monitoring declined. Furthermore, we find that a substantial proportion of employees do not appear to respond at all to manipulations in the monitoring rate. This heterogeneity has important implications for the design of reward systems. On the one hand, monitoring and incentives strategies need to regulate the margin of employees who are opportunistic. On the other hand,

$4 \quad$ Roth and Slonim (1998) demonstrate that it is possible to run laboratory experiments with monetary payoffs as substantial as those found in actual economic relationships. It is far more difficult, however, to reproduce in a lab, relationships lasting weeks, months or years. 
management strategies need to sustain the motivation of the substantial fraction of employees who are generally disinclined to shirk.

The paper proceeds in three sections. In the first two sections we outline a simple economic model of opportunistic behavior in order to clarify the relationship between the rational cheater model and alternative explanations of opportunism. In the third section, we present our empirical findings. The paper concludes by considering the implications of the behaviors we observe for economic analysis and managerial practice.

\section{Theories of Opportunistic Behavior}

The "rational cheater" model of motivation posits that employees are self-interested actors who continuously probe their environment in search of ways to increase their welfare. Opportunistic behaviors, i.e., shirking or cheating, offer the possibility of increasing employee utility at the expense of the employer or customer. According to the rational cheater model, employees will be opportunistic whenever they perceive that the marginal benefits of shirking exceed the marginal costs. Effective management strategies manipulate the perceived costs and benefits of opportunism in order to reduce the attractiveness of shirking.

The rational cheater model provides a powerful and parsimonious framework for the analysis of diverse employment relationships, but it is not the only theory of opportunistic behavior. Two alternative approaches, associated with sociology and psychology, also have wide appeal outside the economics profession. For simplicity we refer to these as the "conscience" and the "impulse control" models.

Though the rational cheater, conscience, and impulse control theories of opportunistic behavior have distinctive empirical predictions, they need not be presented as competing, mutually exclusive, explanations of behavior. We see these explanations as conceivably emerging from an overarching economic model of opportunistic actions in which the distinctive predictions of the rational cheater, conscience, and impulse control models emerge from different assumptions one makes about the parameter values in an individual's utility function. 


\subsection{The Conscience Model}

In the rational cheater model, individuals evaluate behaviors in terms of their perceived consequences. In the conscience model, in contrast, individuals derive utility directly from behaving appropriately. The importance of appropriate behavior is often stressed by stating that opportunistic actions are inconsistent with an individual's "identity." In his Primer on Decision Making, decision scientist James March describes the ways in which the logic of appropriate behavior is distinct from the logic of rational cheating.

When individuals and organizations fulfill identities, they follow rules or procedures that they see as appropriate to the situation in which they find themselves. Neither preferences as they are normally conceived nor expectations of future consequences enter directly into the calculus.... Rule following is grounded in a logic of appropriateness.... The process is not random, arbitrary or trivial. It is systematic reasoning, and often quite complicated. In those respects, the logic of appropriateness is quite comparable to the logic of consequences. But rule-based decision making proceeds in a way different from rational decisionmaking. The reasoning process is one of establishing identities and matching rules to recognized situations. (March, 1994, p.57-58)

Thus a physician may treat all her patients equally regardless of their ability to pay, because this is the behavior consistent with her identity as a "good doctor." In the rational cheater model, in contrast, a physician derives no utility directly from the appropriateness of a behavior. Rather, the physician might engage in this behavior because of the uncomfortable consequences (the threat of suits, professional sanctions, etc.) of discriminating among patients.

In terms of conventional microeconomic models, the passage quoted from March describes the psychological processes that determine the subjective cost of opportunism to an individual. When people say that honesty is core to their personal identity, they are saying that the psychological cost of inappropriate or unethical behavior is very high—so high that they will not actively investigate opportunities for shirking. This same idea is echoed in the sociological and criminological literature on the role of shame and embarrassment as mechanism of social control separate from systems of formal sanctions (Grasmick and Bursik, 1990; Nagin and Paternoster, 1993). 
In the context of employment relationships, the "conscience" model suggests a very different way of managing employment relationships than the rational cheater model. Instead of manipulating the expected consequences of opportunistic actions, managers need to structure the employment relationship so that employees adopt identities inconsistent with opportunism.

Some economic theorists incorporate models of appropriate behavior into models of employment relationships. Akerlof (1982), for example, argues that paying high wages encourages employees to behave according to the rules relating to "gift exchange." The resulting sense of reciprocity and mutual obligation reduces opportunism. Kreps (1997) discusses the possibility that introducing monetary incentives and/or close supervision undermines social identities that result in "intrinsic motivation" to do a good job. Encinosa, Gaynor, and Rebitzer (2000), and Kandel and Lazear (1992), analyze the role peer pressure plays in determining equilibrium levels of work effort. 5

Some human resource managers emphasize the importance of supervisor expectations in shaping employee behavior (Livingston, 1969). Supervisors that expect high levels of performance alter the goals and self-perception of employees in performance enhancing ways. These self-fulfilling expectations can make the job of managing opportunism particularly complex. If heavy handed monitoring sends the message that managers expect employees to be shirkers, it may undermine the intrinsic motivations that limit opportunism. It is possible then, under the conscience model, that increases in monitoring may actually increase employee malfeasance (see also Drago, 1989).

\section{$1.2 \underline{\text { Impulse Control }}$}

Impulse control theories of opportunistic behavior derive from psychology. A central feature is the observation that the attractiveness of a reward is inversely proportional to the delay in receiving it. The desirability of near-term rewards is not the sort one would expect on the

5 Bowles and Gintis (1986) rely on the inconsistencies in the logic of appropriate action in different social settings to construct a general microeconomic theory of social stability and change. 
basis of rational discounting. Rather, individuals put inordinately high value on immediate payoffs - preferring the gratification of a near-term reward at the cost of payoffs with substantially higher present value that are only slightly delayed.

Frank (1988) argues that opportunism in economic relationships stems from the way human brains have evolved to react to near-term rewards.

The addict's problem, apparently, differs in degree, not in kind, from one we all face - namely, how to accord distant penalties and rewards a more prominent role in our behavior. We are all addicts of a sort, battling food, cigarettes, alcohol, television sportscasts, detective novels, and a host of other seductive activities. That our psychological reward mechanism tempts us with pleasures of the moment is simply part of what it means to be a person. In the face of the behavioral evidence, it seems hardly far-fetched to suppose that rational assessments, by themselves, might often fail to assure behaviors whose rewards come mostly in the future (Frank, 1988, p. 88).

Thus, in spite of the best efforts of families, schools and religious institutions, human societies produce a substantial number of individuals who engage in opportunistic behavior because they do not have sufficient impulse control to pass up the immediate rewards from cheating. Indeed, prominent theories of antisocial behavior in criminology and psychology emphasize the central role of poor impulse control in criminal behavior. 6

The impulse control model has distinctive implications for shirking in employment relationships. Firms will try to screen out employees with impulse control problems, but none of the usual methods (psychological tests, interviewing and checking references) will be completely reliable. Firms will therefore have a proportion of employees who will find the short-term gains from shirking quite irresistible. Regulating these impulses requires the imposition of costs that are as immediate and near at hand as the gains from shirking. Frank (1988) argues that the key psychological role of a conscience is to impose immediate costs to offset the immediate gains from shirking. Thus, in contrast to the prediction of the conscience model, a reduction in the short-term costs of shirking should result in an increase in shirking behavior. The longer-term

6 See Gottfredson and Hirschi (1990), Moffit (1993), and Wilson and Herrnstein (1985). 
costs of shirking (i.e., the threat of job loss in the future) will have little effect on behavior. In contrast to the rational cheater model, we would not expect shirking behavior to be strongly related to the value of the employment relationship to the employee.

\section{A Model of Opportunistic Behavior}

In this section we present a simple model of the firm's incentive design problem that incorporates the rational cheater, impulse control and conscience models.

Consider the employer to be a profit maximizing firm where profits are:

$$
\pi=\theta[r(e)+\varepsilon]-[w+b[r(e)+\varepsilon+(1-m) c]]-\alpha(c)-\mu(m) .
$$

The firm's revenues are determined by: $r(e)$, the legitimate pledges earned by a worker who puts in effort $e ; \varepsilon$, a mean-zero random term; and $\theta$, a constant ranging between 0 and 1 . Parameter $\theta$ is determined by both the fraction of donations the firm keeps (as a commission from the client organization) and the fraction of pledges that are honored. We assume $r^{\prime}>0$ and $r$ ' $<0$. Compensation to employees is determined by $w$, the fixed component, and $b$, a linear bonus based on legitimate pledges as well as undetected "cheats." We use $c$ to represent the number of such bad calls in a period and $m$ to represent the rate at which calls are monitored by the employer. Bad calls, i.e. donations reported by employees but subsequently repudiated by donors, are costly to the firm's reputation and annoying to the firm's clients because they cause the firm to try to collect money from people who deny they ever intended to contribute money. ${ }^{7}$ We represent these costs by $\alpha(c)$, where $\alpha^{\prime}>0$. Monitoring is also expensive and we represent these costs by $\mu(m)$, where $\mu^{\prime}(m)>0$.

We write the current period utility, $U$, of a risk neutral worker as:

$$
U=w+b[r(e)+\varepsilon+(1-m) c]-e-\chi(c)
$$

$7 \quad$ The company we study had as clients large non-profits who were very eager to protect their good reputations. In order to retain the trust of these clients, the phone company discouraged its employees from engaging in high-pressure or questionable sales practices that often result in bad calls. 
where $e$ is the monetized disutility of effort and $\chi(\mathrm{c})$ is the subjective psychological cost of cheating. ${ }^{8}$

The flow of utility from the current job in period $t$ is

$$
V_{t}=w+b[r(e)+\varepsilon+(1-m) c]-e-\chi(c)+\beta\left[p q V_{t+1}+(1-p q) V_{A}\right]
$$

where $\beta$ is the gross discount rate, $V_{A}$ is the lifetime utility of the "alternative" to the current job, $p$ is the probability a worker is not detected cheating enough times to warrant dismissal and $q$ is the exogenous probability that a worker stays on the job next period, given that she is not dismissed. We make $p=p(m, c)$ and assume that: $p_{m}<0$ for $\mathrm{c}>0 ; p_{m}=0$ for $\mathrm{c}=0 ; p_{c}<0$ for $m>0$; and $\frac{\partial^{2} p}{\partial c \partial m} \leq 0$. This last condition says that as the firm increases monitoring, the effect of a cheat on dismissal probabilities becomes more pronounced. Conversely, at monitoring rates of 0 the marginal effect of $c$ on $p$ is 0 .

In our set-up, as in the experiment we examine below, the firm has two incentive instruments - pay (determined by $w$ and $b$ ) and monitoring $(m)$ - to regulate two employee activities - effort expended in soliciting pledges $(e)$ and the number of bad calls $(c)$.

We consider first the case in which the direct marginal disutility from making bad calls, $\chi^{\prime}(c)$, is high enough that none are made. This frees the firm to adopt a first-best compensation strategy, i.e., $m=0$ and $b$ is set to ensure optimal effort, $b^{*}=\theta$. In other words, the worker is paid as if she were a residual claimant to the enterprise. ${ }^{9}$ The fixed component of compensation, $w$, is set to meet a participation constraint and is otherwise irrelevant to our problem.

8 The function $\chi(\mathrm{c})$ treats the dissatisfaction from shirking as a purely private affair. Many sociologists would prefer a set-up that treats the disutility of opportunism as an endogenous function of the social setting - especially the degree of opportunism prevailing among other employees. In such an expanded model, social comparisons influence the equilibrium level of shirking without altering the intrinsic disutility associated with $c$. When these social comparisons are important, the equilibrium level of cheating will be greater than would prevail in the absence of social norms (Encinosa, Gaynor, and Rebitzer, 2000, and Kandel and Lazear, 1992). 
The "rational cheater" perspective refers to settings where the firm cannot depend on intrinsic motivation to limit cheating. In this setting the worker chooses $c$, and $e$ in order to maximize:

$$
w+b[r(e)+\varepsilon+(1-m) c]-e-\chi(c)+\beta\left[p q V_{t+1}+(1-p q) V_{A}\right] .
$$

The first-order conditions for a worker's choice of optimal effort $\left(e^{*}\right)$ and cheating $\left(c^{*}\right)$ are, respectively, 10

$$
\begin{aligned}
& b r^{\prime}\left(e^{*}\right)-1=0, \text { and } \\
& b(1-m)+\beta q\left[V_{t+1}-V_{A}\right] \frac{\partial p}{\partial c}-\chi^{\prime}\left(c^{*}\right) \leq 0 .
\end{aligned}
$$

The firm maximizes profits (1) given these response functions - choosing an optimal $b$ and $m$. It is easy to demonstrate that in contrast to the case in which "conscience" is the sole constraint on opportunism, the firm will operate with a positive level of monitoring and relatively lowerpowered incentives $(b<\theta)$. The need for a positive level of monitoring is obvious, and the intuition behind the firm's use of lower-powered incentives is also clear. When a worker is already inclined to cheat, this inclination will be stronger the higher is the bonus $b$. While a high-powered incentive (high $b$ ) is helpful in motivating effort, the use of this incentive must be muted because it provides a strong incentive to cheat. ${ }^{11}$

Rewriting $(5 b)$, we notice that the "cheating condition" can be written

$$
b(1-m) \leq-\beta q\left[V_{t+1}-V_{A}\right] \frac{\partial p}{\partial c}+\chi^{\prime}(c) .
$$

The left hand side of the inequality is the marginal material benefit of cheating while the right hand side is the marginal cost. The second component on the right hand side is the effect of

10 Second order conditions hold if $\frac{\partial^{2} p}{\partial c^{2}}<0$.

11 The logic is the same as in multi-tasking models such as Holmstrom and Milgrom (1991) and Baker (1992). The concern in such models is that when a firm places an incentive on a metered task, it risks reducing the effort an employee will undertake on a second valuable (but unmetered) task. In our setting the two tasks - both valuable from the firm's perspective - are making sales and preserving the integrity of the firm. A high-powered bonus encourages more of the first task but at the potential expense of the second. 
"conscience" which could for some individuals be large enough to dissuade cheating altogether. For workers with an insufficiently strong conscience, the first component on the right hand side - involving the cost of potential job loss-is crucial. All else equal, a worker is disinclined to cheat when the job is valuable ( $q$ and $\left[\mathrm{V}_{\mathrm{t}+1}-\mathrm{V}_{\mathrm{A}}\right]$ are large) and when $\beta$ is large. Monitoring provides the key link between the incentive and desired behavior; the worker limits cheating thanks to fear of detection and dismissal from a valued job. For a worker with an extreme impulse control problems, though, who deeply discounts future events $(\beta \rightarrow 0)$, the monitoring rate is largely irrelevant because the threat of job loss is not of immediate concern. ${ }^{12}$

If individuals are neither extremely myopic nor completely bound by conscience, i.e., if they are rational cheaters, the relationship between monitoring and cheating is clear: the lower the rate of monitoring in a period the higher will be the incidence of cheating. ${ }^{13}$ A reduction in monitoring increases the payoff to the marginal cheat while reducing its expected cost.

It is worth considering a case in which initially the firm has set the monitoring rate high enough that there is virtually no cheating among a group of workers for whom there is heterogeneity in the value placed on the ongoing employment relationship. If the monitoring rate is then reduced, observed increases in cheating would likely be most pronounced among workers who place a low value on the job. It is for these workers that the inequality (6) first becomes binding (and thus $c$ becomes positive) as $m$ declines.

\section{Experimental Design and Empirical Analysis.}

\subsection{The Setting and Design of the Experiment}

The telephone marketing firm we study had 16 geographically dispersed sites. The job of the employees working at these sites was to call potential donors and request contributions.

12 In the economics literature, impulse control is often modeled using something other than conventional discounting (Rabin, 1998). Introducing hyperbolic (or other non-standard) discounting would complicate the exposition without changing the basic point we wish to make.

13 If the reduction in monitoring persists for a long time into the future the net effect is more complex because the value of the current job, and hence $V_{t+1}$, increases as $m$ falls. 
Employees were paid a base salary and also earned a bonus for exceeding pledge targets. As employees approached the target, the marginal benefit of cheating approached the value of the bonus.

Employees were hired with the understanding that some number of their pledges would be checked by a call back or audit. The practice at the firm was to inform employees and supervisors at the end of the week about the number of bad calls detected during the week. Bad calls were deducted from an employee's pay. Some bad calls were likely to be the result of bad luck. Other bad calls more likely reflected employee malfeasance. We refer to calls of this latter type as suspicious bad calls. The incidence of suspicious bad calls (SBCs) is a noisy indicator of shirking. ${ }^{14}$ An employee with a few SBCs was not subject to heavy discipline, but those with an unusually large number of suspicious bad calls could ultimately be dismissed. The rate or frequency of call-backs was not revealed to employees, but could be inferred from the number of bad calls deducted from paychecks at the end of each week.

The design of the experiment was quite simple. For the sixty weeks prior to the experiment, the company had reduced call back rates at all sites from $25 \%$ to $15 \%$ to $10 \%$ (see Table 1 for a description). On June $1^{\text {st }} 1994$, the call-back rate for 12 sites was reduced from $10 \%$ to $5 \%$. This reduction in audit rates freed up the resources needed to increase monitoring to $25 \%$ at the four remaining sites. At these four sites, the audit rate "observed" by employees and supervisors was manipulated by reporting back the results taken from a randomly drawn subsample of the actual call-backs made. The manipulation of the observable audit rate at the four

14 Call-backs happened within hours of the recorded pledge. Suspicious bad calls were defined as call-backs where the phone number was disconnected or where the individual reached claimed that she did not pledge, or only wanted information. 
experimental sites is presented in Table 1. The experimental design allowed for both inter- and intra-site comparisons. 15

The verification data from call-backs was made available to us in two forms: aggregate, weekly data for all 16 sites, and individual level data for employees working in the four experimental sites. The aggregate data extends 60 weeks prior to the experimental manipulation of audit rates and the experiment took place over 14 weeks. We therefore describe the experiment as beginning in week 60, although strictly speaking, individuals will have no knowledge of the manipulation of the monitoring rates until the end of week 61.

\section{2. $\quad$ Results Using Aggregate, Site Level Data}

Weekly data on the ratio of suspicious bad calls to good calls (i.e., pledges that were verified by a call-back) was collected for all 16 sites for 60 weeks prior to the June $1^{\text {st }}$ experiment and for the duration of the experiment.

We investigate the effect of audit rates on suspicious bad calls in a regression framework. The left hand side of Table 2 presents descriptive statistics for the variables of interest. Columns (1) through (4) of Table 2 analyze the ratio of suspicious bad calls to the number of verified calls; columns (1) and (2) are linear probability models and (3) and (4) are grouped logits. The right hand side variables in these estimates were the observable audit rate from the previous week, hours worked at the site during week $t$, the fraction of work hours attributed to employees with eventual tenure less than 2-3 weeks, and the fraction of hours spent on "outreach." Outreach refers to calls made to previous donors as opposed to "cold calls." In addition to these variables, the estimates in Table 2 include site dummy variables.

The key results from Table 2 are that observable audit rates in the previous week have a substantial effect on bad calls in the current week. This relationship, however, is strongest when

15 The four experimental sites were chosen because the number of donations and bad calls at these sites appeared to move relatively closely together. The observable monitoring rates listed in Table 1 were then randomly assigned to each site. 
the audit rate is set to zero. Thus, from columns (1) and (2), we see that sites having observable audit rates of zero in week $t$ experience a 0.03 point increase in the ratio of suspicious bad calls to verified good calls in week $t+1$. This point estimate is substantial considering that the mean value of the dependent variable is 0.02.16 The logit models in (3) and (4) yield results of similar magnitude. While the sharpest changes in behavior occurred at a 0 observable audit rate, the effects of monitoring are statistically significant (and with the expected sign) at higher audit rates as well.

\subsection{Monitoring and the Suspicious Bad Calls Made by Individuals}

The analysis presented in Table 2 relies on aggregate, site level data to investigate the determinants of $S B C s$. The company also made available to us data on the number of audited bad calls made by individual employees for each of the 14 weeks of the experiment. Unfortunately, we were not given any information about employees who did not make bad calls. Thus in order to estimate the response of individuals to variations in the observable audit rates, we need to find a sample of employees at work during the experiment and match these with the data on individual bad calls provided by the company.

One sample of employees is derived from a survey we administered to employees working at the four experimental sites on two days in week 60.17 Assuming that those who answered the survey in week 60 were still employed in week 62, we can use these data to estimate how the experimental manipulation of the observable audit rate in week 61 influenced the bad call rates of individuals in week 62. A second benefit of this employee survey is that it

16 In the first stage of the study, when $25 \%$ of successful calls were audited, call centers reported 1 verified "good" call per hour worked. This suggests that employees were making roughly 4 "sales" per hour or 160 for a 40 hour week.

17 The survey was conducted at the company work sites by researchers from Carnegie Mellon. All respondents were assured that their responses would be completely confidential and that no one from the company would know how they answered the questions. The response rate was nearly $100 \%$, in part because the survey could be filled out very quickly during work hours and individuals who completed the survey were allowed to participate in a raffle of $\$ 100$. 
collected information about the perceived value of the job to employees. We use this information in subsequent sections to investigate more directly the role that the value of the job plays in shaping employee behavior.

Table 3 Panel A presents the data on suspicious bad calls from our sample of employees working at the four experimental sites in week 60. Column (1) reports the number of respondents, while columns (2) and (3) report the total number of suspicious bad calls in weeks 61 and 62 . These increased substantially at the site with an observable audit rate of $0 \%$, Site D. There is no clear pattern of change for the other three call centers.

Employees learn about audit rates at the end of the week, when the bad calls are subtracted from their incentive pay. Thus by comparing the behaviors of those who "got away" with a SBC in week 61 with those who did not, we can learn about the response of employees to monitoring. Column (4) in Panel 3A lists the number of employees at each site who "got away" with an SBC, i.e., who had at least one suspicious bad call that was not reported back to them in week 61. Column (5) reports the rate of suspicious bad calls for these employees in the week after they had a non-reported SBC (week 62). Column (5) is best interpreted in comparison to column (6), the rate of SBCs for those who did not have on unreported SBC. The comparison suggests that the SBC rate in week 62 is higher for those with unreported SBCs in week 61. This difference is especially pronounced in Sites D and B.

If the results in Panel A of Table 3 reflect opportunistic behavior, we should observe different patterns when we investigate non-suspicious bad calls, i.e., bad calls that are purely the result of an employee's bad luck. Panel B presents data on the number of non-suspicious bad calls (NSBCs) made by our sample of employees at the four experimental sites. NSBCs were defined by the employer as pledges where the donor subsequently wanted to cancel their pledge, 
or otherwise changed their mind about contributing. ${ }^{18}$ Since NSBCs are due to bad luck and SBCs are due to an unobserved combination of bad luck and employee malfeasance, comparing the results in panels A and B should give us some insight into the role that luck and malfeasance play in the experiment.

In Panel B we observe that the number of NSBCs fell for three of the four sites during the experiment and, unlike the pattern for suspicious bad calls, the site with an observable audit rate of zero (Site D) did not experience an upsurge in NSBCs. Columns (4) through (6) track the behavior of those who "got away" with a non-suspicious bad call in week 61. Contrary to the results for suspicious bad calls in Panel A, we do not find a dramatic difference between respondents who had at least one NSBC in week 61 and those who did not. In stark contrast to the results in Panel A, we find that in Site D those with non-reported NSBCs in week 61 actually had fewer NSBCs per respondent in week 62 than other respondents. The conclusion we draw is that the results in Panel A of Table 3 reflects some degree of employee malfeasance.

Table 4 analyzes the data in Table 3 in a regression framework. The estimates in column (1) regress the number of SBCs in Week 62 against the number of audited, but not reported, SBCs in Week 61. The relationship between not-reported SBCs and SBCs in the following week is positive and strongly statistically significant. The behavioral significance of the coefficients is also large. For every not-reported SBC in Week 61 we observe 1.27 SBCs in Week 62.

Columns (2) through (5) of Table 4 investigate the robustness of these results. Column (2) introduces as a covariate the reported SBCs in the previous week. This variable proves to be behaviorally and statistically insignificant. Column (3) substitutes not-reported NSBCs for reported SBCs, and column (4) reports estimates when both variables are included in the

18 The distinction between SBCs and NSBCs is consistent with the beliefs of company managers. One of the benefits of call-backs for the company is that they provided an opportunity to "save" bad calls by convincing donors to follow through on their earlier pledge. 
regression. Findings in these columns suggests that it is unreported "suspicious bad calls" rather than bad calls per se that are influencing employee behavior.

In the experiment, observable audit rates were varied exogenously across sites, but individual employees were not randomly assigned to call centers. Thus the possibility remains that opportunistic behavior is due to cross-site differences in employees rather than observable audit rates. Column (5) partially addresses this issue by introducing covariates measuring employee characteristics taken from the employee survey. The variables measure job tenure, weekly hours usually worked at this job, monthly income from the job, educational attainment, number of dependents and marital status. We find that the coefficient on Not-reported SBC's in Week 61 is very similar to that in column (1).

The coefficients in Table 4 suggest that employees do engage in opportunistic behavior when suspicious bad calls are not reported. The aggregate data in Table 2 suggests that opportunistic behaviors are most visible when monitoring rates are set close to 0 . The individual data summarized in Table 3 suggests that much of the action occurs when observable monitoring rates were set to 0 at Site $\mathrm{D}$. This raises the possibility that what we are calling opportunistic behavior is, instead, the result of some feature of Site D other than the observable audit rate. In principle it should be possible to investigate this interpretation of the results because later on in the experiment, the observable audit-rate at Site D is increased and other sites are given an observable audit rate of 0 . Thus by extending our analysis of individual data beyond week 62, we can conduct both intra and inter-site comparisons

In order to extend our analysis, though, we need to observe employee behavior beyond week 62. The turnover rate at the company was sufficiently high and weekly hours were sufficiently irregular that we cannot safely assume that all of the employees who filled out our survey in week 60 would be at work in each week of the experiment. We therefore needed to construct a sample of employees who were employed at the company at points in time after week 62. Unfortunately, as we noted above, the company only supplied us information on the employees who made bad calls in weeks 60-74. 
We can circumvent this data limitation by examining employees who made nonsuspicious bad calls. An employee with at least one non-suspicious bad call in a week must have been at work during that week. Non-suspicious bad calls, as we discussed above, are believed by the employer to be the result of bad luck rather than bad actions. We can, therefore, treat the employees with any NSBCs in a week as a sample of employees at work during week t.

Assuming, as we did in Tables 3 and 4, that an employee at work in week $\mathrm{t}$ will be at work in weeks $t+1$ and $t+2$, we can use the information on NSBC's to construct a rolling, short-term, longitudinal data set that allows us to estimate the determinants of SBC's from weeks 62-74 of the experiment. Specifically, we can estimate the following equation for an individual $i$ at site $s$ in week $t+2$ who had at least one NSBC in weeks $t$ and /or $t+1$.

$$
S B C_{\mathrm{ist}+2}=\alpha_{\mathrm{o}}+\alpha_{1}(\text { Not-Reported } S B C)_{\mathrm{ist}+1}+\varepsilon_{\mathrm{ist}+1}
$$

where $\varepsilon_{i s t+1}$ is a mean zero error term assumed to be uncorrelated with Not-Reported $S B C_{i s t+1}$. In order for this last condition to hold, NSBC in week $t+1$ must be uncorrelated with SBCs in week $t+2 .{ }^{19}$ Estimates in Table 4 indicate that NSBCs in week 61 are not correlated with SBCs in week 62 of the experiment. We assume that it this also the case in subsequent weeks.

Table 5 presents estimates of the relationship between not-reported suspicious bad calls in week t-1 and SBCs in week t. The list of employees generated by each week's list of NSBCs yields an unbalanced time-series cross sectional sample that includes 461 individuals who appear on average 3.5 times in the panel. Some individuals appear more than 10 times in the sample and others only twice.

For purposes of comparison (to Table 4), column (1) of Table 5 estimates the effect of not-reported suspicious bad calls in week 61 on SBCs in week 62. The results here are very close to the results we obtained using the sample of employees who responded to our survey in

19 To see this, remember that individuals are included in our rolling sample if $N S B C>0$ in week $t+1$ and/or $t$. If $N S B C_{t+1}$ was positively correlated with $S B C_{t+2}$, this selection rule would, in effect, be selecting our sample on the basis of the dependant variable. Thus individuals in our sample with few Not-Reported SBC's would be more likely to have high values for $\varepsilon$. 
week 62. A non-reported SBC in week 61 results in 1.3 additional SBCs in week 62. Column (2) repeats the regression for the sample of employees from all the weeks of the experiment. The estimated coefficient on Not Reported SBCs in Week $t-1$ falls substantially but remains positive and both statistically and behaviorally significant; a non-reported suspicious bad call in week t-1 leads to 0.5 additional SBC's in week t. 20 Column (3) shows that the inclusion of site and week dummies does little to alter this estimate.

What explains the fall in the coefficient on Not Reported SBC's in Week $t$-1 in estimates that extend beyond week 62? We find clues to a plausible answer by noting previously discussed patterns in the data. From Table 2, we observe that much of the response to changes in audit rates occurred in sites where the observable call-back rate was set close to zero. We also know, from Tables 3 and 4, that much of the response to "getting away" with a bad call happens within the first week of the incident and that there is a great deal of individual heterogeneity in response. Thus, in the most responsive call center, Site D, we find 16 out of 39 respondents increased SBCs between week 61 and week 62. Analogous numbers for sites A, B and C are, respectively, 4 out of 40,11 out of 50 , and 9 out of 27.21

Based on these findings, it seems that a substantial fraction of the employees (especially at site D and especially in week 62) responded quickly and aggressively to a regime of 0 monitoring. If these highly responsive employees figure out early that "no one is watching," it is reasonable to suppose that "getting away" with further bad call in later weeks will have relatively little additional effect on the behavior of the employee. In short, the estimates in

20 If we re-estimate the equation in column (2) of Table 5 for weeks 63 and beyond the coefficient on Not Reported SBC's in Week t-1 is 0.38 with a t-statistic of 8.14 .

21 In an appendix to this paper, we present additional evidence for heterogeneity from the rolling sample of employees constructed for weeks 62 to 74 . For each week's sample, we calculated the number of SBC's for the median employee and for the employee at the $80^{\text {th }}, 90^{\text {th }}$, and $95^{\text {th }}$ percentile. Averaging these across weeks, we find that the average employee at the median of the distribution made virtually no SBC's. In contrast, the "average" employee at the $95^{\text {th }}$ percentile of the weekly SBC distribution made as many as 9.7 and as few as 2.58 SBC's in a week. 
columns (2) and (3) of Table 5 are "averaging" the large early reaction by some workers with more muted subsequent responses.

If the heterogeneity/rapid response explanation in the previous paragraph is correct, the rapid response of employees requires an explanation. How it is that some employees change behavior dramatically in response to one or two weeks' experience with 0 monitoring? We can illustrate the nature of this problem with some simple "back of the envelope" calculations. If $10 \%$ of calls were monitored, and an employee made an average of 120 good calls per week and 4 deliberate SBCs per week, and 8\% of "good" calls are falsely classified as suspicious, the probability of having zero reported SBCs in a week is 0.25 . Such a worker would thus not think it too unusual to have zero reported SBCs in a given week or even for two consecutive weeks. However, when the monitoring rate is 0 , even a minimal amount of communication between workers would allow workers to infer that the monitoring rate declined. For example, if three workers talking at the water cooler each confirmed having $0 \mathrm{SBCs}$, they would correctly notice that this is unusual (an event with probability 0.016 given our "back of the envelope" assumptions). If these workers then compared notes with additional workers or noticed the absence of SBCs for a second week, they would very quickly ascertain that the monitoring rate had declined. 22

The regressions in Table 5 estimate the effect of "getting away" with a bad call on subsequent behavior. In interpreting these results, we note that our key variable, not-reported suspicious bad calls, is a rather noisy measure of getting away with bad calls in a week. There

22 Most of the action in the experiment occurred at the zero-monitoring site. Clearly the inference problem is easier for workers at this site. In addition, the psychology literature shows that individuals often fail to correctly assess the odds of "getting caught" in circumstances such as the one we study. Kahenman and Tversky (1979) suggest that individuals overstate the likelihood of small probability bad events (such as getting caught fabricating a sale), but perceive zero probabilities accurately. These psychological biases concerning risky decisions would cause employees to respond much more strongly to a monitoring rate of 0 percent than say 2 percent even though the difference between those monitoring rates would not otherwise be particularly important to a rational cheater. 
are at least two sources of "measurement error:" error due to the fact that only a random sample of calls were audited, and error due to fact that some SBCs are the result of bad luck rather than bad actions. As a consequence we likely have attenuation bias in our OLS estimators. Fortunately, we have a natural set of instruments, the exogenously-set monitoring rate prevailing at the site in week $t-1$.

Instrumental variables estimates are presented in columns (4) and (5) of Table 5. In (4), the estimated coefficient on Not Reported SBC's in Week $t$-1 is considerably larger than the comparable OLS estimate (3). In (5) we also include both week and individual fixed effects. ${ }^{23}$ We continue to find that when workers get away with bad calls, thanks to reduced monitoring, they respond with a subsequent increase in cheating. The fact that these results show up in the IV estimation procedure gives increased confidence that the experimental manipulation of monitoring is causing the changed observed behavioral responses in cheating.

\subsection{Employee Heterogeneity}

Patterns observed in Table 3 suggest considerable heterogeneity in employee responses to the experiment. In this section we examine employee heterogeneity more directly. A central prediction of the model of opportunism presented in Section 2 is that the employee's tendency to engage in opportunistic behavior should be related to the value of the current job relative to outside options. We therefore begin our analysis of employee heterogeneity by examining differences in how employees value their job.

To assess the value of the call center job, we made use of employee survey data as well as data on local labor market conditions taken from the US Census. The employee survey (which was distributed in week 60) asked questions about employee perceptions concerning their job and their relationship with the employer. Summary statistics from the employee survey are presented in Table 6. The first question asks, "If you were to look for a new job in your county,

23 We do not have both site and individual fixed effects because no workers transferred across sites. 
how easy would it be for you to find a job with about the same level of pay and benefits as this company?" Nearly $60 \%$ of respondents said that it would be quite difficult or very difficult to find an equivalent job. The second question asks how likely it is the employee will be at the current employer in one year. More than $70 \%$ of respondents thought it almost or somewhat certain that they will still be employed in the next year.

The remaining statistics in Table 6 concerns employee assessments of their treatment by the employer. Employees were asked to respond on a 1 to 5 scale to the following statements: "[the company] cares about my personal well-being;" "[the company] takes advantage of me;" and "[the company] is a good place to work." One striking feature of these tabulations is how many employees have positive feelings toward the employer. Roughly $70 \%$ of employees agree or strongly agree that the company cares about their well-being and more than $90 \%$ agree or strongly agree that the company is a good place to work. Similarly, $71 \%$ disagree or strongly disagree with that the company takes advantage of them.

To ascertain the value of outside job opportunities, we use extracts from the 1990 Census to estimate wage equations for the MSA or county where the call center was located. We then used these estimates, together with demographic information about employees collected in the employee survey, to "predict" the wage that a person with similar characteristics would, on average, receive in the local labor market. ${ }^{24}$ The telephone solicitation company used the same compensation formula at all of its call centers. Thus variations in the predicted wage in the local labor market is a reasonably exogenous determinant of the value of outside alternatives relative to working for the company.

We use the Table 6 data on employee perceptions of their current employment relationship to check the plausibility of the predicted "outside" wage as a measure of the relative

24 The four "experimental" call centers were located in 4 different cities. Each city was in a different county and the counties were in three different states. Thus it is reasonable to suppose that the four call centers were situated in distinct labor markets. Details on the wage equations and the data we used are presented in an appendix. 
value of the current job. Employees with stronger outside options should, ceteris paribus, value the employment relationship less and should be less likely to anticipate staying with the company.

Table 7 presents ordered probit estimates of the relationship between a worker's current earnings, her expected outside earning opportunities (as estimated using Census data), and her perception about outside opportunities, as presented in Table 6. In column (1) we estimate the effect of outside options on the perceived difficulty of finding an equivalent job. Results are as expected: The better an individual's outside options, as measured by our variable Estimated Outside Monthly Earnings, the greater the perceived ease of finding an equivalent job. ${ }^{25}$ Monthly Income At This Job has the opposite effect; the higher one's current income the lower the perceived ease of an equivalent job.

Column (2) in Table 7 concerns the effect of outside options on expected job tenure. Here we observe that neither Estimated Outside Monthly Earnings nor Monthly Income at This Job have a statistically significant relationship with expectations about staying at the job the next year. Students, however, are less likely to stay an additional year and employees with more current job tenure are more likely to expect to stay an additional year.

Columns (3) though (5) examine the relationship between outside job offers and workers' assessments of treatment by the employer. We find that the higher the Estimated Outside Monthly Earnings, the less likely an employee is to agree with the statement that the employer "cares about me" and the more likely they are to agree with the statement that the company

Point estimates indicate that the effect of Estimated Outside Monthly Earnings is substantial. An increase of one standard deviation in Estimated Outside Monthly Earnings (\$258), reduces the probability that the respondent believes an equivalent job will be "very difficult" to find by 0.129 points. (This point estimate was calculated in two steps. First, we used the ordered probit estimates in Table 7 to estimate the probability that each individual will choose one of the four answers. We then regressed the predicted probabilities of choosing "very difficult" against the same right hand side variables used in the ordered probit. The resulting regression coefficients indicate how the mean predicted probabilities vary with the right hand side variables.) 
“takes advantage of me," but Estimated Outside Monthly Earnings has no statistically significant effect on perceptions about whether the company is a "good place to work."

By adding together employee responses to Company Cares About Me and Company Is Good Place to Work and subtracting responses to Company Takes Advantage of Me we can construct a general "attitude scale" that increases as employees' attitudes towards the employer improves. We present this scale in the variable ATTITUDE and examine it's determinants in column (6) of Table 7.26 We find that employee attitudes towards the employer become more negative as their outside earnings options improve. We also find that students are more likely to have negative attitudes towards the employer than other employees. Taken together, the results in Table 7 indicate that measured employee perceptions of the job and the employer move in plausible ways with an objective and independently derived measure of outside earning opportunities.

In Table 8 we investigate how employee perceptions about the value of the job and their attitude towards the employer shape their response to "getting away" with an SBC. Column (1) of Table 8 examines how the perceived difficulty in finding an equivalent job and employee attitudes towards the employer influence the number of SBCs in week 62 . We find that the coefficient on Not Reported SBCs Week 61 in Table 8 is virtually identical to those reported in Table 4. We also observe that the coefficient on ATTITUDE is negative and statistically significant; people with positive attitudes toward the firm cheat less. The coefficient on Difficult to Find Job is small in magnitude and not statistically significant. ${ }^{27}$ The rest of Table 8 explores these results in more detail.

26 More specifically, the variable ATTITUDE = Company Cares About Me + Company Is Good Place to Work - Company Takes Advantage of Me where the attitude variables are standardized (mean 0 , variance 1) versions of the employee attitude variables in Tables 6 and 7. ATTITUDE has a Cronbach's $\alpha=0.80$

27 We also experimented with using Estimated Outside Monthly Earnings to assess the value of the job relative to outside options. We find that this variable also had no effect on SBC's in week 62 . 
One can view the ATTITUDE variable as entering our model of opportunism in two ways. First, a positive attitude towards the employer presumably reflects feelings that, ceterus paribus, increase the value of the job. Alternatively, it may be that employees with positive feelings towards the employer experience heightened disutility when engaging in opportunistic behavior that damages the employer. This heightened disutility may be due to feelings of reciprocity for receiving fair treatment from the employer or may reflect a set of innate psychological traits (such as empathy) that make it easier to feel good about the employer and also raise the psychological costs of bad behavior. ${ }^{28}$

Our model of opportunism suggests that both mechanisms should have a similar influence on the magnitude of any behavioral response to "getting away" with bad calls. As we noted at the end of Section 2, workers who place high value on their job will likely be less responsive to a reduction in monitoring than workers who place a low value on the job. It follows that if ATTITUDE reflects increased value of the job, we should observe that employees with a strongly positive $A T T I T U D E$ will be less responsive than other employees to a reduction in monitoring rates. Similarly, if ATTITUDE reflects the heightened direct disutility of shirking, equation (6) predicts that employees with strongly positive ATTITUDE will respond less strongly to a fall in monitoring and many won't respond at all.

Columns (2) and (3) of Table 8 examine the effect of ATTITUDE on the response of employees to "getting away" with a bad call in week 61. Column (2) is estimated for employees whose score on ATTIUDE is greater than or equal to the sample median and column (3) is estimated for employees with scores below the median. Comparing the estimated coefficients on Not Reported SBCs Week 61 in columns (2) and (3) we find that employees with positive attitudes towards employers do indeed respond less strongly to "getting away" with an SBC than

Similarly in regressions containing both Estimated Outside Monthly Earnings and Difficult to Find $J o b$, the two variables were neither individually nor jointly significant.

28 The relationship between the psychic costs of malfeasance and feelings of reciprocity towards the employer have been discussed in models of "gift exchange" (Akerlof 1982). 
do employees with negative attitudes. For employees with positive attitudes, having a not reported $S B C$ in week 61 increases the number of SBCs in week 62 by 0.89 . For employees with negative attitudes, one would expect an increase of 1.60 SBCs. This $79 \%$ difference is both behaviorally and statistically significant. 29

Taken together, the results in columns (1), (2) and (3) indicate that employees with positive attitudes towards the employer engage in less opportunism and respond less to "getting away" with an SBC. These findings do not, however, allow us to distinguish between the two mechanisms by which ATTITUDE may shape opportunistic behavior-increased value of the job or increased direct disutility from taking advantage of the employer. We can shed some additional light on this question, however, by examining an alternative indicator of the value of the current job. Specifically, if ATTITUDE reflects variations in the value of the job, we might expect our other direct measures of the value of the job to influence opportunistic behavior in similar fashion.

Columns (4) and (5) of Table 8 look in more detail at the Difficult to Find Job variable. We again divide the sample of employees into two groups: those who believe it would not "be difficult" or "very difficult" to find another equivalent job (column (4)) and those who do believe that finding an equivalent job would be "difficult" or "very difficult" (column (5)). Our model predicts that the coefficient on Not Reported SBCs Week 61 should be smaller for those who value the job, in column (5), than for those who place lower relative value on the job, in column (4). We find, however, exactly the opposite pattern. "Getting away" with an SBC in week 61 is associated with 0.73 additional bad calls in week 62 for employees who think it would be easy to find an equivalent alternative job. In contrast, an undetected SBC in week 61 is associated with 
1.31 SBCs in week 62 for the employees in column (5). The estimated $78 \%$ difference in response across the two groups of employees is behaviorally and statistically significant. ${ }^{30}$

In short, evidence from the experiment indicates that employees with positive attitudes towards employers were less responsive to "getting away" with a bad call than were employees with negative attitudes. If this impact of $A T T I T U D E$ were due to the variation in the value employees place on the job (due to the positive feelings toward the employer), we would expect direct measures of the value of the job to have similar effect. Instead we observe that employees who believe they would have a hard time finding an equivalent job are more responsive to "getting away" with an SBC.

In our experiment, employees were not randomly assigned to call centers. Rather they chose to work at the call centers after considering their other opportunities in the labor market. From this perspective, it would not perhaps be surprising that variations in the perceived value of the job within the company (as reflected in Difficult to Find Job) may be too small to have a meaningful effect on opportunism. Our finding that employees who place a high value on the job are significantly more responsive to "getting away" with an SBC is, however, harder to reconcile with our model of opportunism. One possible explanation for this anomaly may rest on a kind of employee heterogeneity that we do not consider in our theoretical analysis. It may be that employees who responded in the survey (in week 60) that their job market prospects are poor believed this because they understood that they had impulse control or other related psychological problems (such as drug or alcohol dependence) that were likely to get them in trouble with employers. These impulse control problems were then revealed as the experiment proceeded (in weeks 61 and 62). Similarly, it may be that employees believed that their job

30 The t-statistic for a test of differences in the estimated values is 2.12. If we re-estimated equations (4) and (5) but divided the sample into employees with high (above the mean) and low (below the mean) values of predicted outside earnings, we get similar results. Employees with low expected outside earnings are 37\% more responsive to getting away with an SBC than other employees. These differences are both behaviorally and statistically significant. 
prospects were poor because they understood that their skills or cognitive abilities where sub-par. There is strong evidence from the psychological literature that cognitive skills and impulse control problems are correlated. ${ }^{31}$

The explanations offered in the preceding paragraph are of course highly speculative. The point we wish to emphasize is that the anomalous results reported in columns (4) and (5) of Table 8 may be consistent with our model of opportunism if there is important and unobserved employee heterogeneity in "impulse control," in worker "conscience," or both. Even with this type of employee heterogeneity, however, the fundamental mechanism of the rational cheater model still plays the key role: workers who have a propensity to cheat-owing to a weak attachment to the firm (or an underdeveloped conscience generally) or to poor impulse controldo in fact increase their cheating when the reward to cheating increases.

\subsection{The Economic Return to Opportunistic Behavior}

The logic of the incentive problem we have studied assumes that individual employees benefit financially from engaging in opportunistic behaviors. We can use the data collected in this experiment to estimate the economic return from shirking.

The equations in Table 9 regress the employee's reported monthly income from the phone company against the number of suspicious bad calls (SBCs) observed in week 60. In columns (1) and (3) we regress income measures against SBCs. In columns (2) and (4) we include additional control variables. The coefficient in column (2) indicates that the number of SBCs made in week 60 are positively associated with earnings. Employees at the $75^{\text {th }}$ percentile of SBCs (i.e., those with $1 \mathrm{SBC}$ in week 60) earned on average $\$ 41.00$ per month more than employees at the median (0 SBCs in week 60$)$. This $5 \%$ increase above mean earnings is consistent with the point estimates in column (4).

31 See, for example, Seguin, et al. (1999), Wallace and Newman (1997), and Wilson and Herrnstein (1985). 


\section{Conclusion}

Much of the economics literature on incentives and employment relationships focuses on a model of opportunism that we dub the "rational cheater model." In contrast, the psychological and sociological literature often emphasize alternative models (that we name the "conscience model" and the "impulse control model"). We argue that the "rational cheater model" and its alternatives can be viewed as variants of an overarching model of opportunistic behavior. We use this model to interpret the results of a unique field experiment that is unusually well suited for examining the economics of opportunistic behavior in employment relationships.

The results indicate that a sizeable fraction of employees behave roughly in accordance with the "rational cheater model:" employees respond to a reduction in monitoring by quickly and sharply increasing the rate at which they engage in malfeasance. We also find, however, that many other employees do not exploit reductions in monitoring to their own advantage. Survey evidence indicates that the employees who responded quickly to reductions in monitoring tended to be those who perceived the employer as being unfair and uncaring. We find suggestive but indirect evidence that this relationship between employee attitudes and malfeasance is more likely due to variations in the disutility of opportunism (as emphasized in the "conscience" model) than to variations in the value of the job (as emphasized in the "rational cheater" model). Having said this, we note that "conscience" alone is not guiding the actions of the workers we observe in the experiment. Workers who are inclined toward opportunism (including, apparently, a number of the workers who view the employer as unfair and uncaring) take advantage of opportunities to cheat when the material advantage of doing so increases.

Any general conclusions drawn from this experiment must be qualified by two key limitations of the experiment. First, while monitoring was manipulated experimentally across sites, individual employees were not randomly assigned to call centers. Rather they chose to work at the call center after comparing it to their alternatives in the local labor market. One implication of this set-up is that intra-organizational variation in the value of the job (relative to alternatives) may not be large enough to have a measurable effect on employee behavior. In 
addition, the absence of random employee assignment makes it is difficult to pin down precisely the role that unobserved employee characteristics play in the patterns of opportunistic behavior that we observe. Second, the experiment occurred under conditions prevailing at one specific company. Although the telephone solicitation company was generally viewed favorably by its employees, the firm also set wages close to the level that many of its employees could find elsewhere, and it functioned with high rates of turnover. Employees also had only a one-time interaction with potential donors and little connection to the organizations on whose behalf they solicited funds. Small employment rents, short expected tenures and brief one-time interactions with customers are probably not the best conditions in which to observe the high levels of intrinsic motivation that form the behavioral cornerstone of the "conscience" model.

The behavioral heterogeneity we observe has important implications for the design and management of reward systems. On the one hand, monitoring and incentives strategies are needed to regulate the margin of employees who are opportunistic. On the other hand, management strategies need to sustain the motivation of the substantial fraction of employees disinclined to shirk. Balancing this tension is tricky, but our findings suggest that management's perceived empathy and fairness in dealing with employees may play an important role in reducing workplace opportunism. 


\section{References}

Akerlof, G. A. (1982). "Labor Contracts as Partial Gift Exchanges,” Quarterly Journal of Economics 97(4): 543-69.

Baker, G. (1992). "Incentive Contracts and Performance Measurement,” Journal of Political Economy 100(3) : 598-614.

Bazerman, M. H., R. Gibbons, L. Thompson and K. L. Valley (1998). "When and Why Do Negotiators Outperform Game Theory?" Debating Rationality: Nonrational Elements of Organizational Decision Making. R. N. Stern and J. Halpern. Ithaca and London, Cornell University Press and ILR Press.

Baron, J. and Kreps D. (1999). Strategic Human Resources: Frameworks for General Managers, John Wilely and Sons.

Berman, Eli (2000). "Sect Subsidy and Sacrifice," Quarterly Journal of Economics 115(3): 905954

Bewley, Truman F. (2000). Why Don't Wages Fall in a Recession? Cambridge, MA, Harvard University Press.

Bowles, Samuel and Gintis, Herbert (1986) Democracy and Capitalism. New York: Basic Books

Camerer, Colin, Linda Babcock, George Loewenstein and Richard Thaler (1997). "Labor Supply of New York City Cabdrivers: One Day at a Time," Quarterly Journal of Economics 112(2): 407-442.

Camerer, C. and R. Thaler (1995). “Ultimatums, Dictators and Manners," Journal of Economic Perspectives 9(2): 209-219.

Cappelli, Peter and Kevin Chauvin (1992). "An Interplant Test of the Efficiency Wage Hypothesis,” Quarterly Journal of Economics 106(3): 769-780.

Drago, Robert (1989). "Supervision and High Wages as Competing Incentives: A Basis for Labour Segmentation Theory," Microeconomic Issues in Labour Economics: New Approaches. Robert Drago and Richard Perlman. New York: Harvester Wheatsheaf.

Encinosa, W., Gaynor, M. and Rebitzer, J. (2000). "The Sociology of Groups and the Economics of Incentives: Theory and Evidence On Incentives in Medical Groups," (Case Western Reserve University Working Paper) .

Frank, R. H. (1988). Passions Within Reason: The Strategic Role of the Emotions. New York, W. W. Norton and Company.

Gaynor, Martin., Rebitzer, James., and Taylor, Lowell (2001). “Incentives in HMOs,” NBER Working Paper \# W8522. 
Gottfredson, M. R., \& Hirschi, T. (1990). A General Theory of Crime. Stanford, C.A.: Stanford University Press.

Grasmick, Harold G. and Robert J. Bursik, Jr. (1990) "Conscience, Significant Others, and Rational Choice: Extending the Deterrence Model,” Law and Society Review 24: 837.

Hall, Brian and Liebman, Jeffery B. “Are CEO's Really Paid Like Bureaucrats?” Quarterly Journal of Economics 113(3): 653-692.

Holmstrom, B. and P. Milgrom (1991). "Multi-task Principal-Agent Analyses: Incentive Contracts, Asset Ownership, and Job Design," Journal of Law, Economics and Organization 7: 24-52.

Kahneman, Daniel and Tversky, Amos (1979). "Prospect Theory: An Analysis of Decision under Risk, Econometrica 47(2): 263-91.

Kandel, E. and E. Lazear (1992). "Peer Pressure and Partnerships,” Journal of Political Economy 100(4): 801-817.

Kreps, D. M. (1997). "Intrinsic Motivation and Extrinsic Incentives," American Economic Review 87(2): 359-364.

Landers, R., Rebitzer J., and Taylor, L. (1996). "Rat Race Redux: Adverse Selection in The Determination of Work Hours in Law Firms," American Economic Review 86(2): 329-48.

Lazear, E. P. (1996). "Performance Pay and Productivity," American Eonomic Review 90(5), 1346-61.

Livingston, Sterling J. (1969). "Pygmalion in Management," Harvard Business Review 47(4) : 81-89.

March, J. G. (1994). A Primer on Decision Making: How Decisions Happen. New York, The Free Press.

Moffitt, T. E. (1993). "Adolescence-limited and life-course persistent antisocial behavior: A developmental taxonomy," Psychological Review 100(4): 674-701

Nagin, Daniel S. and Raymond Paternoster (1993) "Enduring Individual Differences and Rational Choice Theories of Crime," Law and Society Review 27: 467-496.

Pfeffer, J. (1996). Competitive Advantage Through People: Unleashing the Power of the Work Force. Cambridge, MA, Harvard Business School Press.

Prendergast, Canice (1999) "Provision of Incentives In Firms," Journal of Economic Literature, 37(1): 7-63.

Rebitzer, J. (1995). "Is There a Trade-Off Between Supervision and Wages? An Empirical Test of Efficiency Wage Theory," Journal of Economic Behavior and Organization 28(1): 107-29. 
Rabin, Matthew (1998). "Psychology and Economics," Journal of Economic Literature 36(1): 11-46.

Roth, A. E. and R. L. Slonim (1998). "Learning in High Stakes Ultimatum Games: An Experiment in the Slovak Republic," Econometrica 66(3): 569-96.

Seguin, Jean, Bernard Boulerice, Philip Harden, Richard Tremblay, and Robert Pihl (1999). "Executive Functions and Physical Aggression After Controlling for Attention Deficit Hyperactivity Disorder," Journal of Child Psychology and Psychiatry 40: 1197-1208.

Wallace, John F. and Joseph P. Newman (1997). "Neuroticism and the Attentional Mediation of Dysregulatory Psychopathology," Cognitive Therapy and Research 21: 135-56.

Wilson, James Q. and Richard J. Herrnstein. (1985). Crime and Human Nature. New York: Simon \& Shuster. 
Table 1

Observable and Actual Audit Rates During the Experiment actual audit rate is in ()

\begin{tabular}{|c|c|c|c|c|c|}
\hline & \multicolumn{3}{|c|}{ Pre-Experiment } & \multicolumn{2}{c|}{ Experiment } \\
\hline & Week 1-25 & Week 26-44 & Week 45-59 & Week 60-67 & Week 68-74 \\
\hline “Experimental" sites & & & & & \\
\hline Site A & $25 \%(25 \%)$ & $15 \%(15 \%)$ & $10 \%(10 \%)$ & $2 \%(25 \%)$ & $0 \%(25 \%)$ \\
\hline Site B & $25 \%(25 \%)$ & $15 \%(15 \%)$ & $10 \%(10 \%)$ & $5 \%(25 \%)$ & $2 \%(25 \%)$ \\
\hline Site C & $25 \%(25 \%)$ & $15 \%(15 \%)$ & $10 \%(10 \%)$ & $10 \%(25 \%)$ & $10 \%(25 \%)$ \\
\hline Site D & $25 \%(25 \%)$ & $15 \%(15 \%)$ & $10 \%(10 \%)$ & $0 \%(25 \%)$ & $10 \%(25 \%)$ \\
\hline Twelve "control" sites & $25 \%(25 \%)$ & $15 \%(15 \%)$ & $10 \%(10 \%)$ & $5 \%(5 \%)$ & $5 \%(5 \%)$ \\
\hline
\end{tabular}


Table 2

Audits and the Rate of Suspicious Bad Calls

\begin{tabular}{|c|c|c|c|c|c|}
\hline $\begin{array}{l}\text { Sample Means } \\
\text { All Sites }\end{array}$ & $\begin{array}{c}\text { Sample Means } \\
\text { Experimental Sites }\end{array}$ & $\begin{array}{c}(1) \\
\text { All Sites }\end{array}$ & $\begin{array}{c}(2) \\
\text { Exp. Sites }\end{array}$ & $\begin{array}{c}(3) \\
\text { All Sites }\end{array}$ & $\begin{array}{c}(4) \\
\text { Exp. Sites }\end{array}$ \\
\hline \multirow[t]{2}{*}{0.021} & 0.019 & $\begin{array}{l}\text { SBC Rate } \\
\text { OLS }\end{array}$ & $\begin{array}{l}\text { SBC Rate } \\
\text { OLS }\end{array}$ & $\begin{array}{l}\text { (see notes) } \\
\text { Grouped Logit }\end{array}$ & $\begin{array}{l}\text { (see notes) } \\
\text { Grouped Logit }\end{array}$ \\
\hline & & $\begin{array}{c}0.031 \\
(2.692) \\
0.006 \\
(2.807) \\
0.019 \\
(6.291) \\
0.002 \\
(1.358) \\
0.002 \\
(1.203)\end{array}$ & $\begin{array}{c}0.031 \\
(2.783) \\
0.006 \\
(1.477) \\
0.008 \\
(1.865) \\
0.007 \\
(16.924) \\
0.002 \\
(3.572)\end{array}$ & $\begin{array}{c}0.966 \\
(6.969) \\
0.359 \\
(2.148) \\
0.949 \\
(10.688) \\
0.383 \\
(5.032) \\
0.405 \\
(5.595)\end{array}$ & $\begin{array}{c}1.089 \\
(5.357) \\
0.394 \\
(1.704) \\
0.702 \\
(2.945) \\
0.651 \\
(4.170) \\
0.463 \\
(2.969)\end{array}$ \\
\hline $1,240.388$ & $1,315.439$ & $\begin{array}{c}0.000 \\
(1.419)\end{array}$ & $\begin{array}{c}0.000 \\
(1.052)\end{array}$ & $\begin{array}{l}0.000 \\
(2.276)\end{array}$ & $\begin{array}{l}0.000 \\
(1.566)\end{array}$ \\
\hline 0.232 & 0.241 & $\begin{array}{l}-0.012 \\
(1.417)\end{array}$ & $\begin{array}{c}0.001 \\
(0.026)\end{array}$ & $\begin{array}{c}0.072 \\
(0.199)\end{array}$ & $\begin{array}{l}-0.258 \\
(0.351)\end{array}$ \\
\hline 0.605 & 0.612 & $\begin{array}{c}0.006 \\
(3.248) \\
0.002 \\
(0.436)\end{array}$ & $\begin{array}{c}0.009 \\
(2.218) \\
0.006 \\
(0.434)\end{array}$ & $\begin{array}{c}0.145 \\
(2.100) \\
-4.872 \\
(29.917)\end{array}$ & $\begin{array}{c}0.328 \\
(2.318) \\
-4.657 \\
(15.344)\end{array}$ \\
\hline & & $\begin{array}{c}779 \\
0.33827\end{array}$ & $\begin{array}{c}196 \\
0.43271\end{array}$ & $\begin{array}{c}768 \\
0.43832\end{array}$ & $\begin{array}{c}196 \\
0.5025\end{array}$ \\
\hline
\end{tabular}

SBC Rate $=$ SBC's $/$ Good Calls Week $\mathrm{t}$

Observable Audit Rates

dummy variables $=1$ when

Audit Rate in Week $\mathrm{t}-1$ is $0 \%$

Audit Rate in Week $\mathrm{t}-1$ is $2 \%$

Audit Rate in Week t-1 is $5 \%$

Audit Rate in Week t-1 is $10 \%$

Audit Rate in Week t-1 is $15 \%$

Hours Worked at Site Per Week

Fraction Of Workers With Eventual Tenure $<2$ Wks

Fraction of Hours Spent in Outreach

Constant

Call Center Fixed Effects

Observations

Adjusted $\mathrm{R}^{2}$
0.33827
$0.43271 \quad 0.43832$

SBC refers to suspicious bad calls in a week. SBC's are pledges where donor's number is disconnected or where donors claims:

they only wanted information; they did not pledge. Good Calls are call-backs that verified donors pledge. Employees made an average of 4 good calls / hour.

The omitted observable audit rate was $25 \%$.

Estimates in columns (1) and (2) are linear probability models. All t statistics are calculated using "White" standard errors.

Estimates in columns (3) and (4) are grouped logit models. The dependent variable is log(SBC Rate/ (1-SBC Rate))

All data in this table are taken from the 60 weeks prior to the start of the experimental manipulation of percieved monitoring rates. 
Table 3

Analysis of Bad Calls Made by Survey Respondents in Weeks 61 and 62

(3)

Panel 3A: Suspicious Bad Calls

\begin{tabular}{|c|c|c|c|c|c|c|c|}
\hline & & (1) & (2) & (3) & (4) & (5) & (6) \\
\hline $\begin{array}{c}\text { Experimental } \\
\text { Site }\end{array}$ & $\begin{array}{l}\text { Observable } \\
\text { Audit Rate }\end{array}$ & $\begin{array}{l}\text { Number of } \\
\text { Respondents } \\
\text { in Survey }\end{array}$ & $\begin{array}{l}\text { Number of } \\
\text { SBC's in } \\
\text { Week } 61\end{array}$ & $\begin{array}{c}\text { Number of } \\
\text { SBC's in } \\
\text { Week } 62\end{array}$ & $\begin{array}{l}\text { Number of } \\
\text { Respondents } \\
\text { With a Non- } \\
\text { reported SBC in } \\
\text { Week } 61\end{array}$ & $\begin{array}{l}\text { SBC Rate in } \\
\text { Week } 62 \text { for } \\
\text { Respondents } \\
\text { In Col (4) }\end{array}$ & $\begin{array}{c}\text { SBC Rate } \\
\text { Week } 62 \text { for } \\
\text { Respondents } \\
\text { Not In Col (4) }\end{array}$ \\
\hline$A$ & $2 \%$ & 40 & 32 & 11 & 19 & 0.473 & 0.095 \\
\hline$B$ & $5 \%$ & 50 & 41 & 54 & 15 & 2.733 & 0.371 \\
\hline C & $10 \%$ & 27 & 17 & 28 & 3 & 1.333 & 1 \\
\hline D & $0 \%$ & 39 & 81 & 124 & 21 & 5.286 & 0.722 \\
\hline
\end{tabular}

Panel 3B: Non-suspicious Bad Calls

(4)

\begin{tabular}{|c|c|c|c|c|c|c|c|}
\hline $\begin{array}{c}\text { Experimental } \\
\text { Site }\end{array}$ & $\begin{array}{l}\text { Observable } \\
\text { Audit Rate }\end{array}$ & $\begin{array}{l}\text { Number of } \\
\text { Respondents } \\
\text { in Survey }\end{array}$ & $\begin{array}{l}\text { NSBC in } \\
\text { Week } 61\end{array}$ & $\begin{array}{l}\text { NSBC in } \\
\text { Week } 62\end{array}$ & $\begin{array}{c}\text { Number of } \\
\text { Respondents } \\
\text { With a Non- } \\
\text { Reported NSBC's } \\
\text { in Week } 61\end{array}$ & $\begin{array}{l}\text { NSBC Rate in } \\
\text { Week } 62 \text { for } \\
\text { Respondents } \\
\text { in Col. } 4\end{array}$ & $\begin{array}{l}\text { NSBC's rate } \\
\text { Week } 62 \text { for } \\
\text { Respondent } \\
\text { not in Col. } 4\end{array}$ \\
\hline$A$ & $2 \%$ & 40 & 39 & 14 & 22 & 0.455 & 0.222 \\
\hline B & $5 \%$ & 50 & 24 & 28 & 16 & 1 & 0.3529 \\
\hline C & $10 \%$ & 27 & 18 & 18 & 7 & 1 & 0.55 \\
\hline D & $0 \%$ & 39 & 40 & 27 & 17 & 0.4118 & 0.909 \\
\hline
\end{tabular}

SBC refers to suspicious bad calls in a week. SBC's are pledges where donor's number is disconnected or where donors claims: they only wanted information; they did not pledge.

NSBC refers to non-suspicious bad calls in a week. NSBC's are pledges for which the donor claims they have changed their minds about their pledge or want to cancel the pledge. 
Table 4

Determinants of Suspicious Bad Calls (SBC's) in Week 62

Dep. Variable

Not Reported SBCs in Wk 61

Reported SBCs in Wk 61

Not Reported NSBC

Tenure (in years)

(1.376; 1.805)

Usual Hrs/ Wk. $=20-30$

(0.541; 0.500)

Usual Hrs/ Wk. $=30$

$$
\text { (0.391; 0.490) }
$$

Currently a Student

$$
\text { (0.308; 0.464) }
$$

Monthly Income This Job

$$
\text { (727.93; 268.702) }
$$

High School or GED

$$
\text { (0.383; 0.488) }
$$

Some College or 2 Yr. College

$$
\text { (0.429; 0.497) }
$$

Degree from 4 yr. College or Grad School

$$
\text { (0.098; 0.298) }
$$

\# Dependents Who You Support

$$
\text { (0.812; 1.238) }
$$

\section{Married}

(0.421;0.496)

\section{Constant}

Number of Observations

Adjusted $\mathrm{R}^{2}$

$\begin{array}{ccccc}(1) & (2) & (3) & (4) & (5) \\ \text { OLS } & \text { OLS } & \text { OLS } & \text { OLS } & \text { OLS } \\ \text { SBC in } & \text { SBC in } & \text { SBC in } & \text { SBC in } & \text { SBC in } \\ \text { Week 62 } & \text { Week 62 } & \text { Week 62 } & \text { Week 62 } & \text { Week 62 }\end{array}$

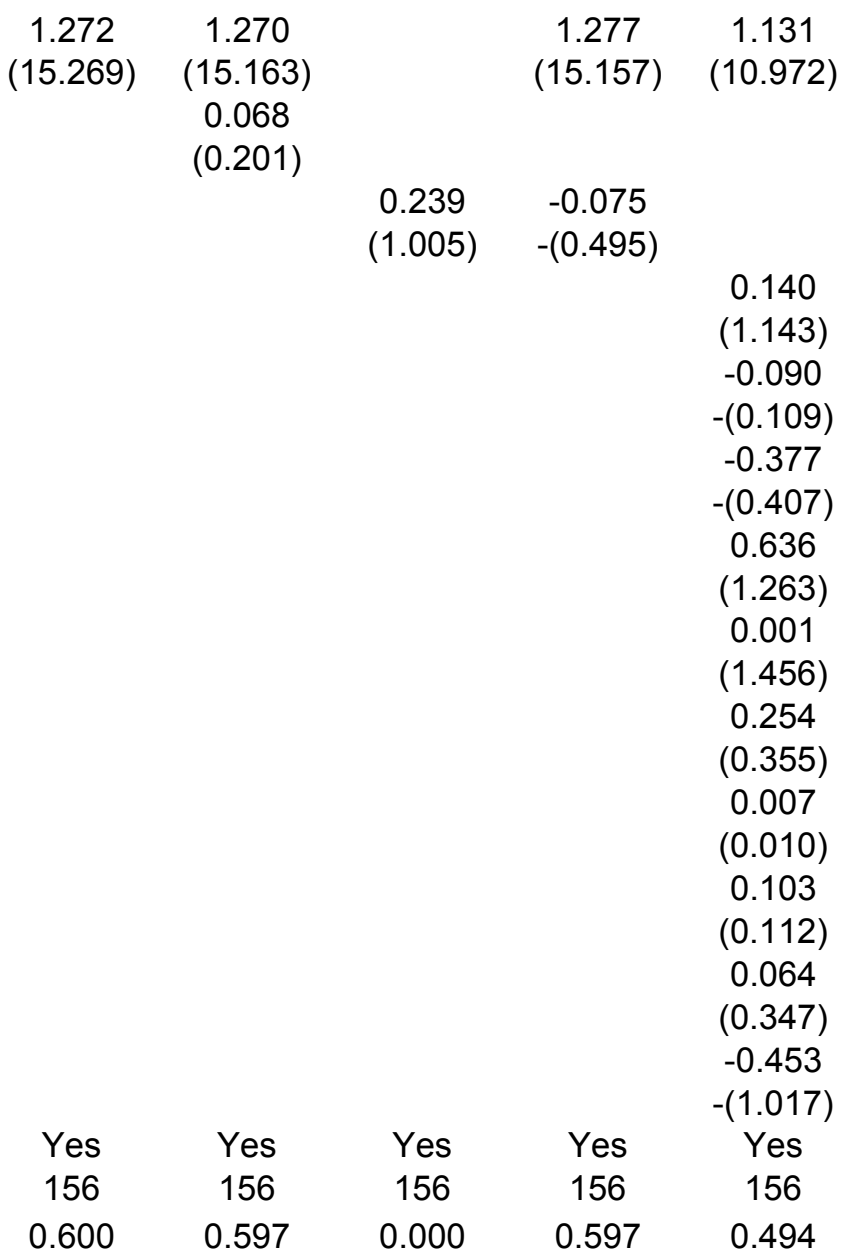

SBC are suspicious bad calls. NSBC are not suspicious bad calls

The company called back $25 \%$ of calls at experimental site, and reported a random sample of these back to employee and supervisor Not Reported SBC are the number of suspicious bad calls not reported to employee at end of week.

Numbers in ( ) are t-statistics. Numbers in ( ; ) under variable names are the mean and standard deviation of right hand side variables in [5]

In column [4] can reject hypothesis that coefficient on Not Reported SBC in Wk 61 is the same as Reported in Wk $61, F(1,153)=11.67$ 
Table 5

Determinants of Suspicious Bad Calls (SBC's)

(2)

$\begin{array}{cccccc}\text { OLS } & \text { OLS } & \text { OLS } & \text { OLS } & \text { 2SLS } & \text { 2SLS } \\ \text { SBC in } & \text { SBC in } & \text { SBC in } & \text { SBC in } & \text { SBC in } & \text { SBC in } \\ \text { Week 62 } & \text { Weekt } & \text { Weekt } & \text { Weekt } & \text { Weekt } & \text { Week } t\end{array}$

$\begin{array}{lcccccc}\text { Not Reported SBC in Week t-1 } & 1.293 & 0.484 & 0.468 & 0.151 & 0.792 & 0.683 \\ & (5.414) & (6.320) & (6.205) & (4.760) & (11.280) & (3.820)\end{array}$

\section{Week $t-1$}

Dummy Variables for Site

Dummy Variables for Week

Dummy Variables for Individual

\section{Observations}

Number of Individuals

$$
\text { (6.205) }
$$

(11.280)

(3.820)

Column 1 is restricted to those with NSBC's in week 60 , the rest of the columns are for the entire sample.

The instrumental variables used in columns (5) and (6) are dummy variables for the observed audit rates at a site in week $\mathrm{t}-1$

The t-statistics in columns (1)-(4) are calculated using robust standard errors allowing for clustering of observations by employee.

The t-statistics in columns (5) and (6) are calculated using robust standard errors allowing for clustering of observations by site.

The mean value of Others' Not Rep. SBC's in Week $t-1$ is 29.6 with a standard deviation of 27 
Table 6

Heterogeneity in Employee Attitudes About the Job and Employer

\section{Attitudes Towards The Job}

How Easy to Find An Equivalent job? (152 respondents)

\begin{tabular}{ccccc} 
very easy & quite easy & quite difficult & very difficult & Total \\
\hline $13.82 \%$ & $26.32 \%$ & $51.32 \%$ & $8.55 \%$ & $100.00 \%$ \\
\hline
\end{tabular}

How Likely Is it That You Will Be Working for [this company] in 1 year? (153 respondents)

\begin{tabular}{ccccc} 
Almost Certain & Somewhat Certain & Unlikely & Very Unlikely & Total \\
\hline $39.87 \%$ & $33.33 \%$ & $11.11 \%$ & $15.69 \%$ & $100.00 \%$ \\
\hline
\end{tabular}

\section{Attitudes Towards the Employer}

Company Cares About Me? (155 Respondents)

\begin{tabular}{|c|c|c|c|c|c|}
\hline Strongly & \multicolumn{3}{|c|}{ Neither Agree nor } & \multicolumn{2}{|l|}{ Strongly } \\
\hline Disagree & Disagree & Disagree & Agree & Agree & Total \\
\hline $4.52 \%$ & $9.68 \%$ & $24.52 \%$ & $44.52 \%$ & $16.77 \%$ & $100.00 \%$ \\
\hline \multicolumn{6}{|c|}{ Company Takes Advangage of Me? (155 respondents) } \\
\hline Strongly & & Neither Agree nor & & Strongly & \\
\hline Disagree & Disagree & Disagree & Agree & Agree & Total \\
\hline $27.74 \%$ & $34.19 \%$ & $26.45 \%$ & $5.16 \%$ & $6.45 \%$ & $100.00 \%$ \\
\hline
\end{tabular}

Company Is a Good Place To Work? (155 respondents)

\begin{tabular}{cccccc}
$\begin{array}{c}\text { Strongly } \\
\text { Disagree }\end{array}$ & Disagree & $\begin{array}{c}\text { Neither Agree nor } \\
\text { Disagree }\end{array}$ & Agree & $\begin{array}{c}\text { Strongly } \\
\text { Agree }\end{array}$ & Total \\
\hline $3.23 \%$ & $3.23 \%$ & $12.26 \%$ & $56.13 \%$ & $25.16 \%$ & $100.00 \%$ \\
\hline
\end{tabular}


Table 7

Determinants of Employee Attitudes Towards Job and Employer

\begin{tabular}{|c|c|c|c|c|c|}
\hline $\begin{array}{l}\text { ordered probit } \\
\text { (1) }\end{array}$ & $\begin{array}{c}\text { ordered probit } \\
(2) \\
\text { How Likely Is it } \\
\text { That You Will Be }\end{array}$ & $\begin{array}{l}\text { ordered probit } \\
\text { (3) }\end{array}$ & $\begin{array}{l}\text { ordered probit } \\
\text { (4) }\end{array}$ & $\begin{array}{c}\text { ordered probit } \\
\text { (5) }\end{array}$ & $\begin{array}{l}\text { OLS } \\
(6)\end{array}$ \\
\hline $\begin{array}{c}\text { How Easy to } \\
\text { Find An } \\
\text { Equivalent job? }\end{array}$ & $\begin{array}{l}\text { Working for [this } \\
\text { company] in } 1 \\
\text { year? }\end{array}$ & $\begin{array}{c}\text { Company Cares } \\
\text { About Me }\end{array}$ & $\begin{array}{c}\text { Takes } \\
\text { Advangage of } \\
\text { Me }\end{array}$ & $\begin{array}{c}\text { Company Is a } \\
\text { Good Place } \\
\text { To Work }\end{array}$ & $\begin{array}{c}\text { ATTITUDE } \\
\text { (towards } \\
\text { employer) }\end{array}$ \\
\hline-0.0020 & 0.0002 & -0.0009 & 0.0010 & -0.0002 & -0.0007 \\
\hline -(4.159) & $(0.360)$ & -)(2.043) & (2.290) & -(0.555) & (1.930) \\
\hline 0.0015 & -0.0004 & 0.0008 & -0.0004 & 0.0001 & 0.0004 \\
\hline (3.178) & $-(0.889)$ & (1.805) & $-(0.933)$ & $(0.161)$ & $(1.180)$ \\
\hline 0.0410 & 0.8043 & -0.3288 & 0.6524 & -0.6127 & -0.4489 \\
\hline (0.158) & (3.143) & $-(1.342)$ & (2.595) & $-(2.384)$ & $-(2.200)$ \\
\hline 0.0238 & -0.1386 & -0.0413 & 0.1494 & -0.0315 & -0.0730 \\
\hline (0.366) & $-(1.942)$ & $-(0.672)$ & (2.408) & $-(0.496)$ & $-(1.440)$ \\
\hline 119 & 121 & 121 & 121 & 121 & 121 \\
\hline-133.10518 & -141.51234 & -166.84824 & -166.8609 & -139.52455 & \\
\hline
\end{tabular}

Estimated Outside Monthly Earnings (z-statistic or, in col. 6, t-statistic)

Monthly Income This Job

(z-statistic or, in col. 6, t-statistic)

Currently A Student

(z-statistic or, in col. 6, t-statistic)

Current Job Tenure

(z-statistic or, in col. 6, t-statistic)

Observations

Log-Likelihood of ordered probit

$\mathrm{R}^{2}$ of ordinary least squares regression

\section{(2)}

Estimates in columns 1-5 are ordered probits, but OLS regression produces similar results.

Monthly Income This Job was collected from survey of employees.

Estimated Outside Monthly Earnings is predicted monthly earnings estimated from an earnings equation estimated for local labor market using 5\% PUMS Census Sample. Earnings equations are presented in an appendix

In column 1, an increase in the dependent variable means an equivalent job is more difficult to find.

In column 2 an increase in the dependent variable means the employee is less likely to stay a year

In columns 3-5, an increase in the dependent variable means employee more strongly agrees with the statement

The mean of Estimated Outside Monthly Earnings is $\$ 599$ with a standard deviation of $\$ 257$

The average of Estimated Outside Monthly Earnings / Monthly Income This Job $=0.89$

The variable ATTITUDE is a scale constructed from the dependent variables in columns (3)-(6). It increases as impression of employer improves.

ATTITUDE = Company Cares About Me + Company Is Good Place to Work - Company Takes Advantage of Me.

This scale is constructed by summing across standardized (mean 0 , variance 1) variables. Cronbach's $\alpha=0.8$ 
Table 8

Employee Heterogeneity and Suspicious Bad Calls

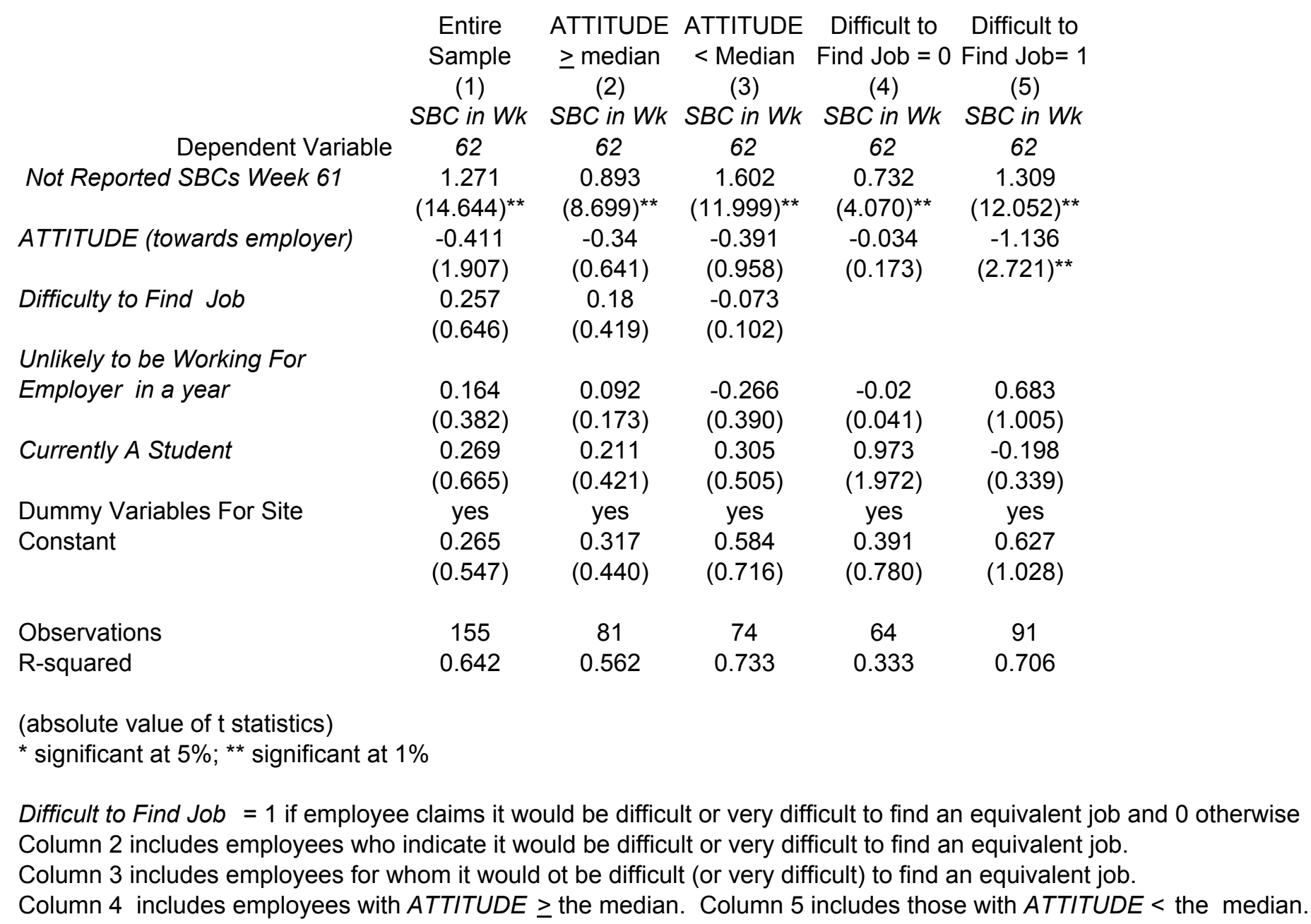




\section{Estimates of The Effect of Shirking On Employee Earnings}

\begin{tabular}{|c|c|c|c|c|}
\hline \multicolumn{5}{|r|}{ arnings } \\
\hline & (1) & $(2)$ & $(3)$ & $(4)$ \\
\hline & & & $\log$ & $\log$ \\
\hline & Monthly & Monthly & Monthly & Monthly \\
\hline & Income & Income & Income & Income \\
\hline & This Job & This Job & This Job & This Job \\
\hline$S B C$ in Week 60 & 54.758 & 41.311 & 0.078 & 0.056 \\
\hline & $(2.970)$ & $(2.383)$ & $(2.812)$ & (2.063) \\
\hline Tenure (in years) & & 123.033 & & 0.183 \\
\hline & & $(2.908)$ & & $(2.732)$ \\
\hline Tenure $^{2}$ & & -14.101 & & -0.021 \\
\hline & & $-(2.182)$ & & $-(2.069)$ \\
\hline Age & & 15.230 & & 0.024 \\
\hline & & $(1.875)$ & & $(1.862)$ \\
\hline$A g e^{2}$ & & -0.216 & & 0.000 \\
\hline & & $-(2.156)$ & & $-(2.184)$ \\
\hline Usual Hrs/ Wk. $=20-30$ & & 355.742 & & 0.577 \\
\hline & & $(4.713)$ & & $(4.838)$ \\
\hline Usual Hrs/ Wk. $=30$ & & 572.571 & & 0.844 \\
\hline & & $(7.298)$ & & $(6.816)$ \\
\hline Married & & 49.338 & & 0.081 \\
\hline & & $(1.288)$ & & $(1.333)$ \\
\hline Currently a Student & & -79.140 & & -0.125 \\
\hline & & $-(1.596)$ & & $-(1.599)$ \\
\hline High School or GED & & -119.463 & & -0.147 \\
\hline & & $-(1.800)$ & & $-(1.399)$ \\
\hline Some College or 2 Yr. College & & -119.744 & & -0.162 \\
\hline & & $-(1.831)$ & & $-(1.569)$ \\
\hline Degree from 4 yr. College or Grad School & & -62.651 & & -0.129 \\
\hline & & $-(0.722)$ & & $-(0.940)$ \\
\hline Constant & 709.833 & 94.975 & 6.502 & 5.541 \\
\hline & $(29.801)$ & $(0.560)$ & $(180.263)$ & $(20.688)$ \\
\hline Adj. $R^{2}$ & 0.056 & 0.424 & 0.050 & 0.369 \\
\hline Observations & 133 & 128 & 133 & 128 \\
\hline
\end{tabular}

All estimates are ordinary least squares. Numbers in ( ) are t-statistics

Dependent variable is monthly income at this company as reported by employees in employee surveys

Similar estimates result if we include dummy variables for each site, and the site variables have no statistically significant effect on earnings. This is consistent with the company policy of using single compensation scheme for all sites. 


\section{Appendix}

\section{Earnings Equations for Each Call Center}

In order to calculate outside options for employees at different call centers, we estimated earnings equations for the local labor market in which the call centers were located. The data we used were from the 1990 Census. Our sample included 5\% of all persons aged 16-90 who reported having worked in 1989. The variables and the earnings equations we estimated are reported in Table A1. 
Table A1

Wage Equations Used To Preduct Outside Earnings for Each Site

Mean Dependent Variable

\section{Male}

Usual Hrs/ Wk. $=20-29$

Usual Hrs/ Wk. $=30$

Usual Hrs/Wk. $=31=40$

Usual Hrs. $/ W k=40+$

Married

Currently a Student

High School or GED

Some College or 2 Yr. College

Degree from 4 yr. College or Grad School

Age

Age $^{2}$

Constant

Adj. $R^{2}$

Observations
(1)

(2)

(3)

Log

Monthly

Earnings

7.2630

Earnings

Earnings

7.1431

0.3423121

(15.767)

0.5939548

(12.016)

0.7583104

(11.969)

1.371219

(32.207)

1.575951

(33.930)

0.1107979

(4.450)

$-0.0736$

$-(2.046)$

0.0566

(1.544)

0.2007

(5.596)

0.4447

(11.018)

0.0695

(14.466)

$-0.0007$

$-(13.032)$

4.0457

(42.036)
0.5796
3511

\subsection{7}

(19.614)

0.5319

(12.019)

0.7260

(11.864)

1.2455

(32.207)

1.3767

(32.972)

0.1255

(5.097)

$-0.0867$

$-(2.366)$

0.1450

(4.605)

0.2316

(6.859)

0.5732

(15.084)

0.0508

(11.772)

$-0.0005$

-(10.709)

4.3712

(50.390)
0.273

(44.792)

0.5020

(30.980)

0.6947

(36.004)

1.2096

(32.207)

1.4463

(96.225)

0.1210

(18.483)

$-0.0849$

$-(9.308)$

0.1606

(16.622)

0.3144

(34.937)

0.6532

(64.995)

0.0573

(43.420)

$-0.0006$

-(36.589)

4.3688

(162.280)

0.502

4632

$\begin{array}{ll}0.4748 & 0.5326 \\ 50215 & 40951\end{array}$

All estimates are ordinary least squares. Numbers in ( ) are t-statistics.

The dependent variable is the log of monthly wage or salary income in 1989.

Monthly income is calculated by dividing wage or salary income in 1989 by usual hours worked per week in 1989 , and multiplying by 4.3

Columns (1)-(4) are estimates for sites A, B, C and D respectively.

Data is from the 1990 Census. Observations are 5\% of all persons who reported having worked in 1989.

The sample for sites $A$ and $B$ were drawn from the county in which the sites are located. The sample for sites $C$ and $D$ were taken from the MSA in which the sites are located. 
Appendix Table A2

The Distribution of SBC's

Across Employees and Within Sites

\begin{tabular}{ccc|c|c|c|c|} 
& & \multicolumn{6}{c}{ Avgerage Number of SBC's For Employee at } \\
Site & Obs. Audit Rate & Weeks & 50 th Centile & 80th Centile & 90 th Centile & 95th Centile \\
\hline A & $2 \%$ & $62-67$ & 0.00 & 0.67 & 1.77 & 2.58 \\
& $0 \%$ & $68-73$ & 0.17 & 0.97 & 2.00 & 3.10 \\
\hline B & $5 \%$ & $62-67$ & 0.17 & 1.00 & 2.45 & 4.34 \\
& $2 \%$ & $68-73$ & 0.17 & 1.27 & 2.70 & 5.20 \\
\hline C & $10 \%$ & $62-67$ & 0.33 & 1.37 & 2.37 & 3.30 \\
& $10 \%$ & $68-73$ & 0.00 & 0.57 & 1.25 & 1.33 \\
\hline D & $0 \%$ & $62-67$ & 0.33 & 3.00 & 5.60 & 9.79 \\
& $10 \%$ & $68-73$ & 0.33 & 2.23 & 3.63 & 5.48 \\
\hline
\end{tabular}

This table presents information on the distribution of SBC's taken from the rolling sample of employees at the four experimental sites. The true audit rate was $25 \%$ at these sites.

For each week's sample, we calculated the number of SBC's for the median employee and for the employee at the 80th, 90th, and 95th centile. The results in columns 4-7 are averages calculated using each week's distribution of SBC's. 
